\title{
Characteristic Studies of Plasma Treated unidirectional Hildegardia Populifolia Fabric
}

\author{
C. Venkata Prasad,, D.W. Lee*, P. Sudhakara*, D. Jagadeesh ${ }^{*}$, B.S. Kim ${ }^{* *}$, S.I. Bae ${ }^{*}$ and J.I. Song ${ }^{*+}$
}

\begin{abstract}
This study deals with effect of plasma treatment on the properties of unidirectional ligno cellulosic fabric Hildegardia Populofolia (HDP) fabric. Thermal stability of the fabric was determined by differential scanning calorimetry (DSC) and Thermo gravimetric analysis (DSC). Morphological properties was analyzed by SEM analysis and found that the surface was rough upon plasma treatment which provides good interfacial adhesion with matrix during composite fabrication. Thermal stability and mechanical properties of the plasma treated fabric slightly increases compare to alkali and untreated fabric. It was observed that tensile properties of the fabric increases upon plasma treatment due to the formation of rough surface. SEM analysis indicates formation of rough surface on plasma treatment which helps in increasing the interfacial interaction between the matrix (hydrophobic) and fabric (hydrophilic).
\end{abstract}

Key Words : Plasma treatment, Hildegardia populofolia, Thermal properties, Morphology.

\section{Introduction}

One of the naturally occurring uniaxial fabrics (rare in occurrence) is botanically known as Hildegardia Populifolia (HDP), which belongs to Malvaceae family. It is widely spread in the eastern slopes of the Kalrayan Hills of Tamil Nadu, India[1]. Recently, the incorporation of ligno cellulosic materials in polymer matrices has become considerable interest $[2,3]$.

Renewable natural fibers have attracted many researchers with their properties. They showed many advantages over synthetic fibers and have been intensively studied in recent years. A non renewable and synthetic fiber causes environmental problems associated with their use and disposal. For this reason, most of the researchers concentrated to find new, renewable and biodegradable fibers/fabrics. Recently, research on natural fibers (Sisal, Flax, Ramie, Grewia tenax, etc.) increases, this is because they offer many advantages over synthetic non-renewable fibers (E-Glass, Carbon, Aramide etc,). In certain applications (automobile, aerospace etc.) require high strength and stiffness. Hence there is a need to improve the adhesion between reinforcement (hydrophilic) and polymer matrix (hydrophobic). Surface treatment of the natural fibers was used to modify the structural morphology. Reports on various treatments are available in the literature[4-6].

Methods to modify the surface and to improve mechanical properties of the fibers are different according to the type of matrix. The most common treatments to modify the fibers surface is removing the superficial layer, changing the topography and the chemical nature of the surface. Organic fibers generally have smooth surfaces and little superficial energy, which result in low adherence to the matrix. These interfacial adhesion in environments where humidity is high and temperature is between 20 and $60^{\circ} \mathrm{C}[7]$. It has been recognized that plasma treatment change the superficial properties of the material based on the formation of free radicals on the surface as a

접수: 2012년 12월 03일, 수정: 2013년 2월 13일, 게재승인: 2013년 2월 15일

* Advanced Composite Materials Laboratory, Dept. of Mechanical Engineering, Changwon National University, South Korea

*+ Advanced Composite Materials Laboratory, Dept. of Mechanical Engineering, Changwon National University, South Korea, Corresponding Author(E-mail:jisong@changwon.ac.kr)

** Composites Materials Group, Materials Processing Division, Korea Institute of Materials Science, Changwon, South Korea 
result of the impacts with the energetic particles (electrons, ions, etc.) traveling in the plasma. Plasma is an ionized gas containing a mixture of ions, electrons, neutral and excited molecules and photons[8]. During atmospheric air pressure plasma (AAPP) treatment, a high frequency electric current excites a feeding gas usually compressed air, into relatively low temperature plasma. Depending on the type and nature of the feed gases used, a variety of surface modifications can be achieved, including an increase or decrease of the surface energy, surface cross-linking and the introduction of reactive free groups[9]. The plasma treatment duration, magnitude of power, distance from the plasma nozzle to the substrate have been shown to be extremely important for the optimization of interfacial shear strength (IFSS) and the eventual composite properties as suggested by Yuan et al. $[10,11]$.

The objective of the present study is to investigate the effect of plasma treatment on the properties of HDP fabric. This paper also explains the structural changes by FTIR, thermal stability, surface morphologies and mechanical properties of the treated and untreated fabrics.

\section{Materials and methods}

\subsection{Materials}

HDP fabric (Kadiri hills, Andhra Pradesh, India), Sodium hydroxide ( $5 \%$ aqueous $\mathrm{NaOH}$ ) (Dae-Jung Chemicals, South Korea) used as received without further purification Acrylic acid was distilled to remove inhibitors before using for plasma polymerization. Double Distilled water collected in the laboratory was used throughout the work.

\subsection{Extraction of the fabric}

HDP fabric (Kadiri Hills, Andhra Pradesh, India) was extracted from tree branches as per the procedure reported elsewhere [12]. The fabric was obtained in the form of knitted layers $(450-700 \mathrm{~cm})$ from the sheath of the tree. The fabric was soaked in water for 3-4 weeks to remove the gum and greasy material and cleaned with double distilled water and dried in air until constant weight. A photograph of the untreated fabric is shown in figure 1. The plasma apparatus used in the present study is schematically represented in figure 2. Plasma treated HDP fabric for different exposure time was designated as HDPX (where $\mathrm{X}=30,60,90$ and $120 \mathrm{sec})$.

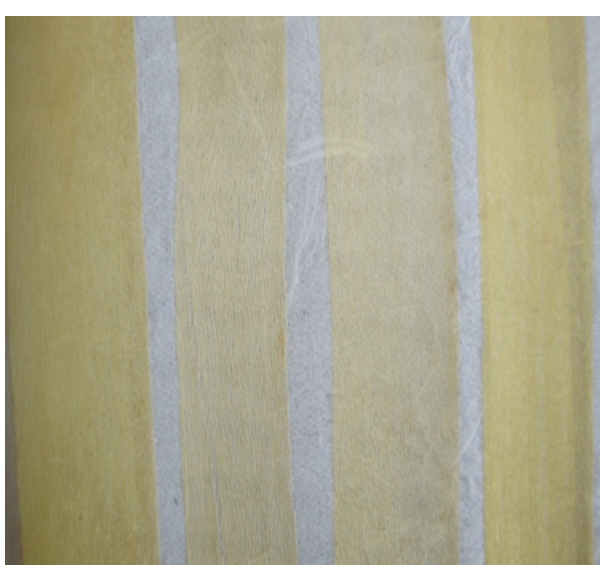

Fig. 1 Photograph of the untreated HDP fabric.

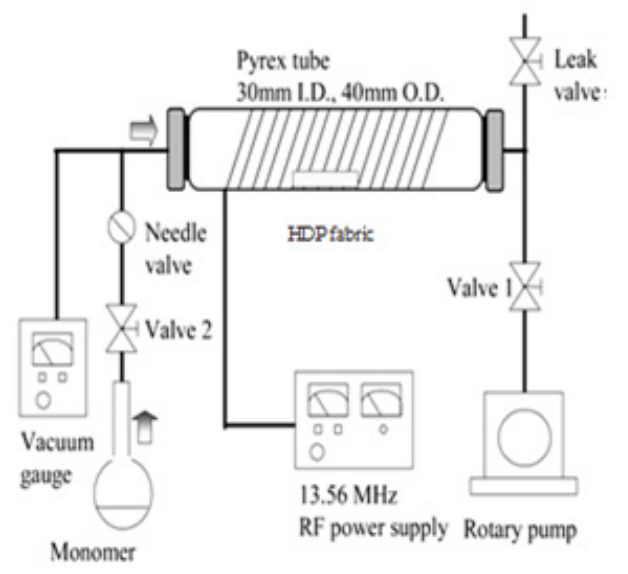

Fig. 2 Plasma treatment apparatus.

\subsection{Fourier transform infrared spectroscopy}

The fabric specimens were characterized using attenuated total reflectance Fourier transform infrared spectroscopy (Perkinelmer, Spectrum GX Model, USA) to study the chemical composition and the structural changes occurred on alkali and plasma treatment. The spectrum of the fabric was scanned in the range of $500-4000 \mathrm{~cm}^{-1}$.

\subsection{Thermo gravimetric analysis}

About $10-12 \mathrm{mg}$ of the fabric powder sample ground in liquid nitrogen was used for the analysis.TGA analysis of the untreated, alkali treated and plasma treated fabrics was carried out using TG instruments SDT Q600 instrument (Made: USA). The analysis was carried out at a heating rate of $10^{\circ} \mathrm{C} / \mathrm{min}$ in the presence of nitrogen atmosphere at a nitrogen flow rate of $100 \mathrm{ml} / \mathrm{min}$. 


\subsection{Fourier transform infrared spectroscopy}

The fabric specimens were characterized using attenuated total reflectance Fourier transform infrared spectroscopy (Perkinelmer, Spectrum GX Model, USA) to study the chemical composition and the structural changes occurred on alkali and plasma treatment. The spectrum of the fabric was scanned in the range of $500-4000 \mathrm{~cm}^{-1}$.

\subsection{Thermo gravimetric analysis}

About 10-12mg of the fabric powder sample ground in liquid nitrogen was used for the analysis.TGA analysis of the untreated, alkali treated and plasma treated fabrics was carried out using TG instruments SDT Q 600 (Made: USA). The analysis was carried out at a heating rate of $10^{\circ} \mathrm{C}$ in the presence of nitrogen atmosphere at a nitrogen flow rate of $100 \mathrm{ml} / \mathrm{min}$.

\subsection{Differential scanning calorimetry}

DSC analysis of the untreated, alkali treated and plasma treated fabrics was carried out using TG instruments SDT Q 600 (Made: USA). The analysis was carried out at a heating rate of $10^{\circ} \mathrm{C}$ in the presence of nitrogen atmosphere at a nitrogen flow rate of $100 \mathrm{ml} / \mathrm{min}$.

\subsection{Scanning electron microscopy}

Scanning electron microscope (SEM; JEOL JSM Model 6360) was used for to study the surface morphological properties of the fabric specimens after sputter coating with gold (JEOL JFC-1600).

\subsection{Mechanical properties}

Mechanical tests of the samples were performed using universal testing machine (Model: Instron 3369) at a cross head speed of $5 \mathrm{~mm} / \mathrm{min}$ and an operating load of $5 \mathrm{kN}$ with an initial accelerating voltage of $10 \mathrm{kV}$. In each case five specimens were measured and the values reported are averages.

\subsection{Chemical composition of Natural fibers}

The chemical composition of natural fibers varies depending on the type of fiber, origin, age of the plant. Normally, natural fibers contain cellulose, hemicelluloses, halo cellulose, pectin, lignin and other waxy materials. The properties of the fabrics depend upon the composition of the individual constituents. Fibers containing higher amount of cellulose show superior mechanical properties. Hemi cellulose is responsible for the biodegradation, moisture absorption and thermal degradation of the fibers. The \% of each of these components varies for different fibers. Generally, the natural fiber contains $60-80 \%$ cellulose, 5-20\% lignin and 8-15\% moisture. The chemical composition of the HDP fabric is presented in Table 1.

Table 1 Chemical composition of various natural fibers

\begin{tabular}{c|c|c|c|c|c}
\hline $\begin{array}{c}\text { Name of } \\
\text { the fiber }\end{array}$ & $\begin{array}{c}\text { Cellulose } \\
\text { (wt \%) }\end{array}$ & $\begin{array}{c}\text { Lignin } \\
\text { wt \%) }\end{array}$ & $\begin{array}{c}\text { Hemi-cellulose } \\
\text { (wt \%) }\end{array}$ & $\begin{array}{c}\text { Pectin } \\
\text { (wt \%) }\end{array}$ & $\begin{array}{c}\text { Moisture } \\
\text { content } \\
\text { (wt \%) } \\
{[13]}\end{array}$ \\
\hline \hline Jute & $61-71.5$ & $12-13$ & $13.6-20.4$ & 0.4 & 12.6 \\
\hline Hemp & $70.2-74.4$ & $3.7-5.7$ & $17.9-22.40$ & 0.9 & 10 \\
\hline Kenaf & $31-39$ & $15-19$ & 21.5 & --- & 12 \\
\hline Flax & 71 & 2.2 & $18.6-20.6$ & 2.3 & 10 \\
\hline Ramie & $68.6-76.2$ & $0.6-0.7$ & $13.1-16.7$ & 1.9 & 8 \\
\hline Sisal & $67-78$ & $8-11$ & $10.0-14.2$ & 10 & 11 \\
\hline coir & $36-43-$ & $41-45$ & $10-20$ & $3-4$ & 8 \\
\hline Lyocell & 60 & 28 & -- & -- & - \\
\hline
\end{tabular}

\section{Results and discussion}

\subsection{FTIR Analysis}

The infrared spectra of untreated (UT), alkali treated (AT) and alkali/plasma treated (APT) HDP fabric are presented in figure 3 . From figure 3 it is evident that there was a visual change in the peaks at 3384, 1729, 1628, and $1021 \mathrm{~cm}^{-1}$. The intensity of the band around $3384 \mathrm{~cm}^{-1}$ increased on alkali treatment, indicating an increase in the $\mathrm{OH}$ content of the fabric. This may be due to an increase in water absorption on the surface of the fabric. This is further indicated by increase in intensity of the peak at $1628 \mathrm{~cm}^{-1}$, which corresponds to the absorbed water.

Moreover, the intensity of the peak around $1024 \mathrm{~cm}^{-1}$, corresponding to $\mathrm{COOH}$ stretching, also increased on alkali treatment. Though the fabric was dried before recording the infrared spectra, the presence of water is still indicated in the spectra. This, in all probability, corresponds to the bound water attached to the cellulose peak around 1729 $\mathrm{cm}^{-1}$, corresponding to the $\mathrm{C}=\mathrm{O}$ stretching of hemicelluloses in the UT fabric, is slightly decreased in the spectrum of AT fabric. This indicates the partial elimination of hemicelluloses after treatment with sodium hydroxide. There was no change in the intensity of the peak around 1508 $\mathrm{cm}^{-1}$, a result of the aromatic skeletal ring vibration of the lignin[14]. Upon plasma polymerization, an additional peak at $2118 \mathrm{~cm}^{-1}$ is observed in the APT spectra indicating the formation of a polymer film on the surface of the fabric. 


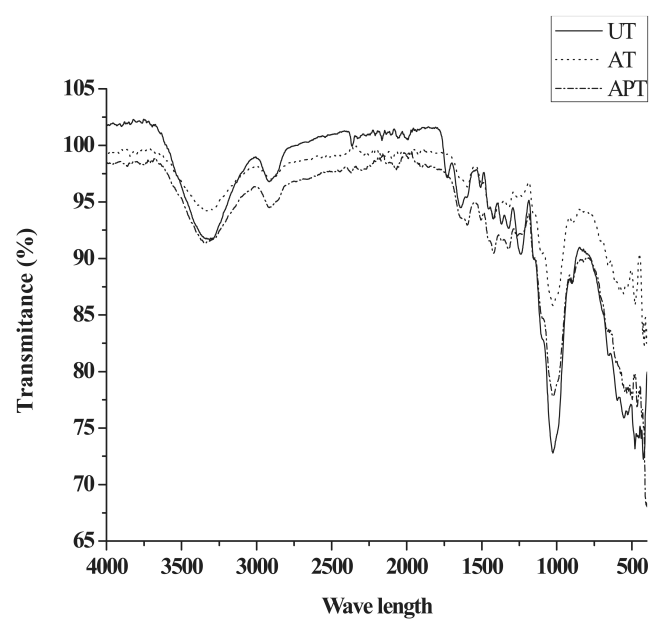

Fig. 3 FTIR analysis of HDP fabric.

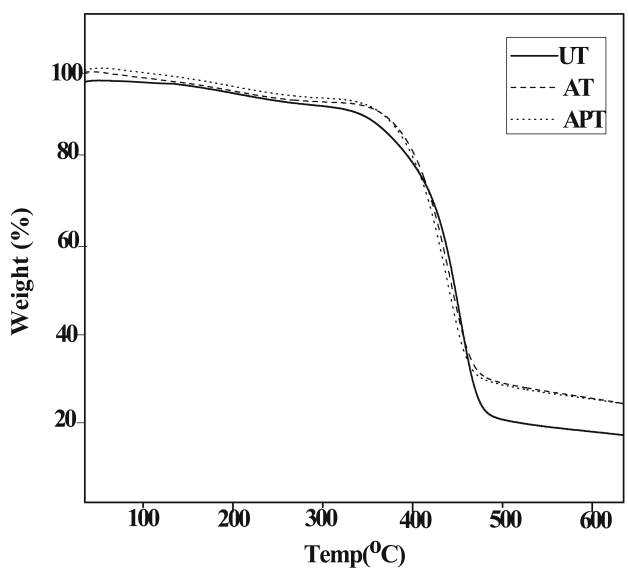

Fig. 4a TGA themograms of HDP fabric.

\subsection{Thermo gravimetric analysis}

As thermoplastic composites are becoming popular at present, the authors studied the thermal stability of the HDP fabric, to assess the possibility of their use as reinforcement. Figure 4 presents the TGA and DTA analysis of the HDP fabric. Figure 4 represents the weight losses in the fabric. The first peak at around $100^{\circ} \mathrm{C}$ in the entire sample may be due to the loss absorbed moisture. A pronounced weight loss of $35 \%$ was observed in the range of $340-480^{\circ} \mathrm{C}$ in case of AT and APT fabric, where as in case of UT fabric is $47 \%$ within the same temperature range, this loss may be due to disintegration of cellulose units. A third weight loss was observed at around $480^{\circ} \mathrm{C}$ in case of the UT, AT and APT fabric; this might be due to degradation of molecular

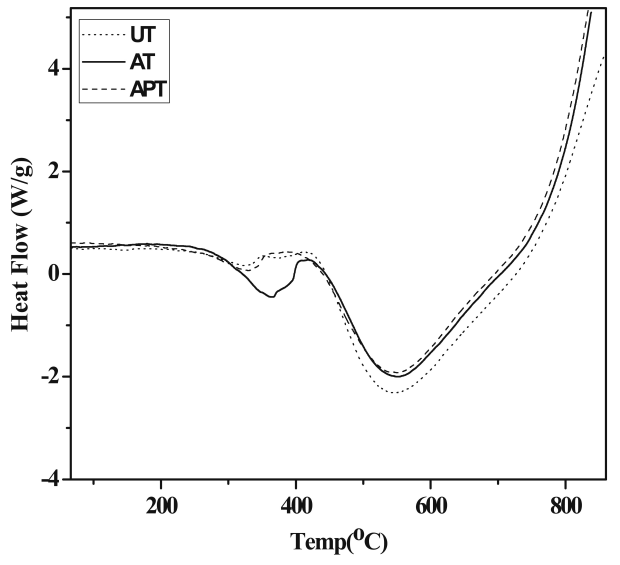

Fig. 4b DTA themograms of HDP fabric.

chains. In case of UT, AT and APT the residual content after $480^{\circ} \mathrm{C}$ is 34,36 and $18 \%$, respectively. Hence, it is concluded that the thermal stability of APT fabric is more compare to AT and UT fabric. Hence, the fabric can be effectively used as reinforcement in composite fabrication. Similar results were also reported by Rajulu et al[15].

\subsection{Differential Scanning Calorimetry}

Figure 5 shows the DSC curves of untreated and treated fabrics. Untreated fabric shows higher glass transition temperature $(\mathrm{Tg})\left(213^{\circ} \mathrm{C}\right)$ than alkali treated fabric $\left(134^{\circ} \mathrm{C}\right)$. This indicates that the decrease in $\mathrm{Tg}$ is due to the removal of amorphous materials (hemicelluloses and lignin) in treated fabric, indicating an increase in crystallinity of the fabric. Further increase in $\mathrm{Tg}$ was observed on Plasma treatment compare to alkali treated. It was observed a little effect on $\mathrm{Tg}$ with increasing the plasma exposure time this might be due to the fabric damage on longer exposure time.

\subsection{Morphological Studies}

The scanning electron micrographs of UT, AT and APT (30, 60, 90, $120 \mathrm{sec})$ HDP fabric are presented in Figure 6. Figure 6 reveals the surface morphology of the fabric; the fibers aligned parallel to each other in uniaxial direction (void regions) which helps in penetrating the polymer matrix through the voids leading to good binding between fabric and polymer matrix during composite fabrication.

Furthermore, in case of the untreated fabric, a white and dark combination layer is found on the surface of the fabric this might be due to presence of waxy material. Whereas, in case of alkali treated fabric these structures were removed 


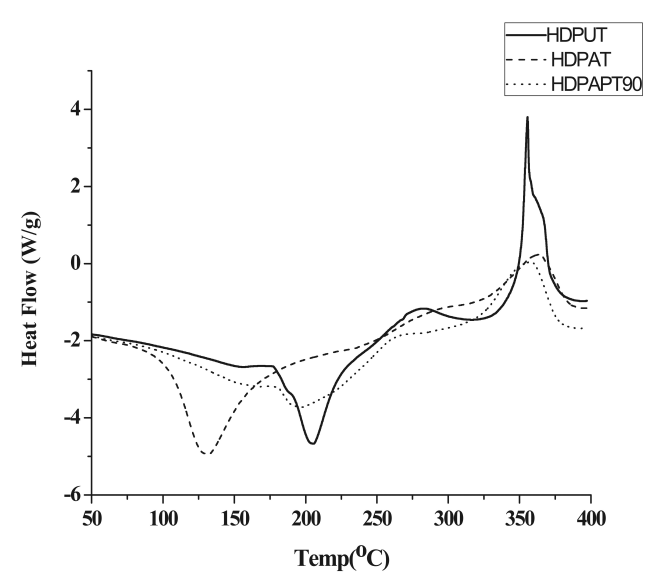

Fig. 5 DSC analysis of HDP fabric.

off due to the elimination of waxy and amorphous materials. Similar results were also observed in our earlier studies in case of Grewia tenax fabric[12].

On plasma treatment the surface of the fabric becomes rough which intern helps for better interlocking which further leads to better interfacial interaction between fabric and used as reinforcement in composite manufacturing. On Increasing the plasma exposure time, increase in surface roughness was observed up to $90 \mathrm{sec}$ (optimum exposure time) beyond 90 sec, crack formation was observed indicating the damage on surface of the fabric. These defects may be partially due to the etching effect of plasma and exposure to elevated temperature during plasma treatment, which may expand the flaws already present on the fabric. The deterioration of the surface morphology is more severe after 90 sec of treatment as greater amount of cracks, pits and deeper corrugations are visible. Similar observations were also reported by Jimenez et al. $^{16}$ in case of other lingo cellulosic fibers.

\subsection{Tensile properties}

Table 2 shows the tensile strength and modulus of HDP fabric. From table 2, it was observed that both tensile strength and modulus increased of the fabric increased on treatment. On plasma treatment further increase in tensile strength and modulus was observed. This increasing trend might be due to the removal of loosely structured material (lignin and hemi celluloses) and the formation of poly acrylic acid layer.. Hence, one can expect that the improved properties can be obtained on using APT fabric as the reinforcement in any polymer matrix (thermo plastic and thermoset)[17].
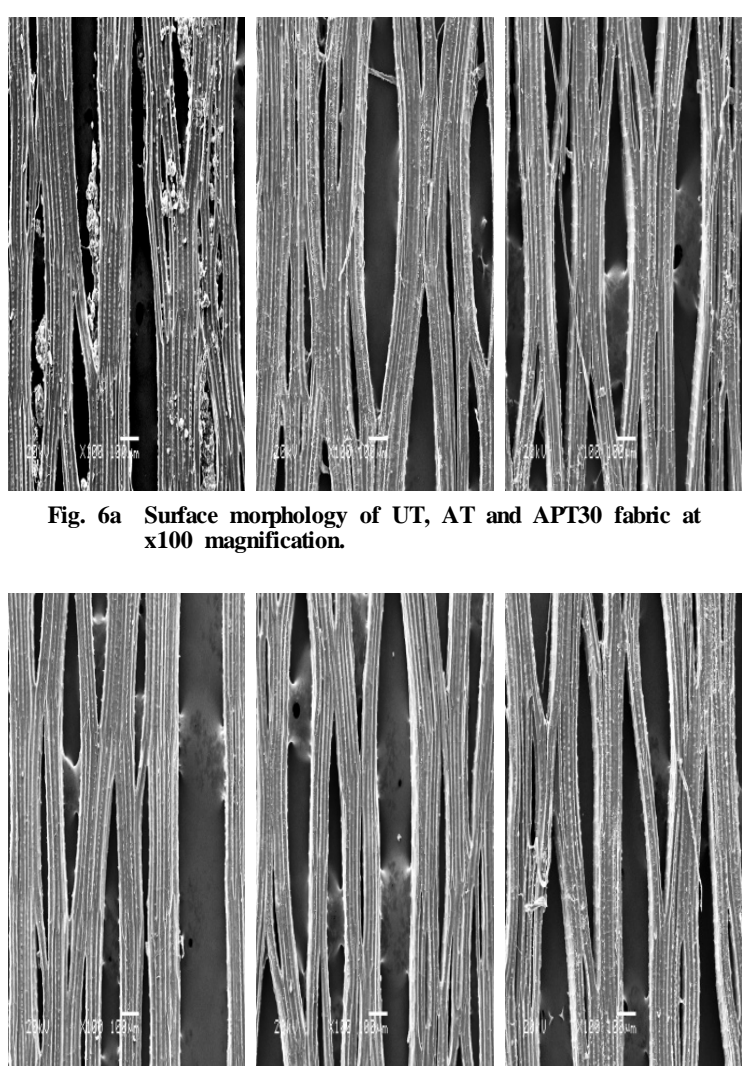

Fig. 6b Surface mophology of APT60, APT90, APT 120 at x100 magnification.

Table 2 Tensile properties of HDP fabric

\begin{tabular}{c|c|c|c}
\hline S.No & Fabric type & $\begin{array}{c}\text { Tensile Strength } \\
(\mathbf{m P a})\end{array}$ & $\begin{array}{c}\text { Tensile } \\
\text { Modulus(GPa) }\end{array}$ \\
\hline \hline 1 & UT & 83.24 & 2.81 \\
\hline 2 & AT & 110.43 & 3.16 \\
\hline \multirow{3}{*}{3} & APT30 & 119.02 & 4.82 \\
& APT60 & 120.65 & 3.91 \\
& APT90 & 122.30 & 3.93 \\
& APT120 & 121.69 & 3.68 \\
\hline
\end{tabular}

\section{Conclusion}

It was observed that the tensile properties of the fabric increases upon plasma treatment due to the formation of rough surfaces. SEM analysis revealed the formation of rough surfaces upon plasma treatment. The rough surface of APT fabric helps in increasing the interfacial interaction between the matrix (hydrophobic) and fabric (hydrophilic) 
when use in composite fabrication. The overall properties of APT HDP fabric are well improved compare to untreated and alkali treated fabrics.

\section{Acknowledgement}

The authors are thankful for the National Research Foundation of Korea (NRF) grant funded by the Korea Government (MEST) (No.2012-0009455, 2012-00008302). This research is also financially supported by Brain Korea (BK21) Projects Corps of the second phase.

\section{References}

1) Ahmedullah, M., Nayar, M.P., and Sastry, A.R.K., Hildegardia populifolia, Red Data Book of Indian Plants, Botanical Survey of India, Calcutta. Vol. 3, 1990, pp. 251-253.

2) Alexandre, G., Takanori, M., Koichi, G., and Junji, O., "Development and effect of alkali treatment on tensile properties of curaua fiber green composites," Composite Part A: Applied Science and Manufacturing, Vol. 38, No. 8, 2007, pp. 1811-1820.

3) Venkata, R.G., Khanam, P.N., Sobha, R.T., Chowdoji, R.K., Naidu, S.V., Bulletin of Pure and Applied Science, 26C (1), 2007, pp. 17-24.

4) Tserkia, V., Zafeiropoulosb, N.E., Simonb, F., and Panayiotoua, C., "A study of the effect of acetylation and propionylation surface treatments on natural fibres," Composite Part A: Applied Science Manufacturing, Vol. 36, No. 8, 2005, pp. 1110-1118.

5) Marianne, T., Sedan, D., Peyratout, C., Bonnet, J.P., Smith, A., Guinebretiere, R., Gloaguen, V., and Krausz, P., "Influence of various chemical treatments on the composition and structure of hemp fibres," Composite Part A: Applied Science Manufacturing, Vol. 39, No. 3, 2008, pp. 514-522.

6) Venkata, R.G., Venkata, P.C., Chowdoji, R.K., Sobha, R.T., and Subha, M.C.S., "Tensile and lignocellulosic properties of Prosopis chilensis natural fabric," Journal of Applied Polymer Science, Vol. 117, No. 5, 2010, pp. 2907-2914.

7) Li, Z.F., Netravali, A.N., "Surface modification of UHSPE fibers through allylamine plasma deposition. I. Infrared and ESCA study of allylamine plasma formed polymers," Journal of Applied Polymer Science, Vol. 44, No. 2, 1992, pp. 319-331.

8) Shenton, M.J., Lovell-Hoare, M.C., and Stevens, G.C., "Adhesion enhancement of polymer surfaces by atmospheric plasma treatment," Journal of Physics D: Applied Physics, Vol. 34, No. 18, 2001, 2754-2760.

9) Bledzki, A.K., Reihmane, S., and Gassan, P.J., "Modification methods for vegetable fibres for natural fibre composites," Journal of Applied Polymer Science, Vol. 59, 1996, 1329-1336.

10) Yuan, X., Jayaraman, K., Bhattacharyya D., "Effects of plasma treatment in enhancing the performance of wood fibre-polypropylene composites," Composite Part A, Vol. 35, No. 12, 2004, 1363-1374.

11) Yuan, X., Jayaraman, K., and Bhattacharyya, D., "Mechanical properties of plasma-treated sisal fibre-reinforced polypropylene composites," Journal of Adhesive Science Technology, Vol. 18, No. 9, 2004, pp.1027-1045.

12) Venkata P.C., Chowdoji, R.K., Venkata, R.G., Sobha, R.T., Swamy, B.Y., and Subha, M.C.S., "Characteristic Studies of Ligno-Cellulosic Fabric Grewia tenax,” Journal of Natural fibers, Vol. 7, No. 3, 2010, pp. 194-215.

13) Cao, K.G., "Research and development of fully green composites reinforced with natural fibers," Journal of Solid Mechanics and Material Engineering, Vol. 1, No. 9, 2007, pp. 1073-1084.

14) Ray, D., Sarkar, B.K., "Characterization of alkali-treated jute fibers for physical and mechanical properties," Journal of Applied Polymer Science, Vol. 80, No. 7, 2001, pp. 1013-1020.

15) Rajulu, A.V., Rao, G.B., Rao, B.R.P., A. Reddy, "Properties of ligno-cellulose fiber Hildegardia," Journal of Applied Polymer Science, Vol. 84, No. 2, 2001, pp. 2216-2221.

16) Baltazar-y-Jimenez, A., Bistritz, M., Schulz, E., "Atmospheric air pressure plasma treatment of lignocellulosic fibres: Impact on mechanical properties and adhesion to cellulose acetate butyrate," Composite Science and Technology, Vol. 68, No. 1, 2008, pp. 215-227.

17) Rajulu, A.V., Rao, G.B., Devi, L.G., “Tensile properties of Natural fabric Hildegardia populifolia/polycarbonate toughened epoxy composites,” Polymer Composite, Vol. 25, No. 6, 2004, pp. 563-568. 